\title{
Atypical Gunshot Injury to the Ear: A Case Report
}

\author{
Sai Spoorthi Nayak, Ehrlson De Sousa, Saumyata Neeraj \\ Department of ENT, Goa Medical College, Goa, India \\ Email: Saumyata16@gmail.com
}

Received 5 February 2015; accepted 24 February 2015; published 28 February 2015

Copyright (C) 2015 by authors and Scientific Research Publishing Inc.

This work is licensed under the Creative Commons Attribution International License (CC BY). http://creativecommons.org/licenses/by/4.0/

c) (i) 0pen Access

\begin{abstract}
Bullet injuries to head and neck are usually associated with high mortality and morbidity due to a number of vital structures lying in close proximity. We present a rare case of air-gun injury with an unusual entry wound. The pellet having a simple trajectory was lodged into middle ear avoiding all important structures.
\end{abstract}

\section{Keywords}

Bullet, Perforated Tympanic Membrane, Metallic Foreign Body

\section{Introduction}

Bullet injuries are a very rare occurrence in a peace loving state as ours. Civilian firearms in Goa are either accidental or suicidal and very rarely homicidal. Penetrating injuries to the middle ear are usually caused by ear buds, Q-tips, pencils, hairpins, etc., which have very localized injury and predictable path. However, penetrating bullet injury to the ear with virtually no entry wound is in itself a rare occurrence. A very unique case of penetrating bullet injury came walking to our casualty with as minimal damage to the ear as one could possibly imagine.

In the event of any trauma to face, our innate sense of protection is directed towards the eyes and face. We instinctively turn away from any approaching insult exposing one of our ears to projectiles, blows, blasts, etc. The pinna and temporal bone encase and deflect injury from deeper middle ear and inner ear structures. But once the pinna and external auditory canal are by passed, the fragile tympanic membrane and subsequently the middle ear are readily damaged.

\section{Case Report}

A 23 years old male presented to our casualty with history of accidental gun-shot to the right ear by an unknown 
person. The patient presented with earache and bleeding from right ear and sudden conductive hearing loss of around $40 \mathrm{~dB}$ (Figure 1).

On examination, there was only a minor abrasion on the right pinna in the cymba concha with pooling of blood in external auditory canal; obscuring the view of tympanic membrane. However no entry wound was visible. Facial nerve functions were normal.

HRCT temporal bone revealed multiple artefacts with streaking in the external auditory canal and middle ear going upto the Eustachian tube. The ossicles appeared intact. The facial nerve canal, inner ear and carotid canal were spared (Figure 2 and Figure 3).

The patient was taken up for exploratory tympanotomy under local anaesthesia. Examination under microscope revealed traumatic perforation of the tympanic membrane through which the bullet was seen lodged in the middle ear. The skin of the external auditory canal was avulsed. Bullet fragments were seen to be lodged in the roof of external auditory canal. Mucosa of the middle ear was also found to be avulsed. The entire bullet was found to be in the anterior mesotympanum with no damage to the ossicles whatsoever (Figure 4).

The bullet fragments were removed and the tympanic membrane was reconstructed using the patient's own temporalis fascia.

The patient was hospitalized for about a week for intravenous antibiotics and discharged on $7^{\text {th }}$ post-operative day after suture removal. He was followed up every week for 3 months. Post-operative hearing documented on audiogram on $3^{\text {rd }}$ post-operative month was recorded as normal (Figure 5).

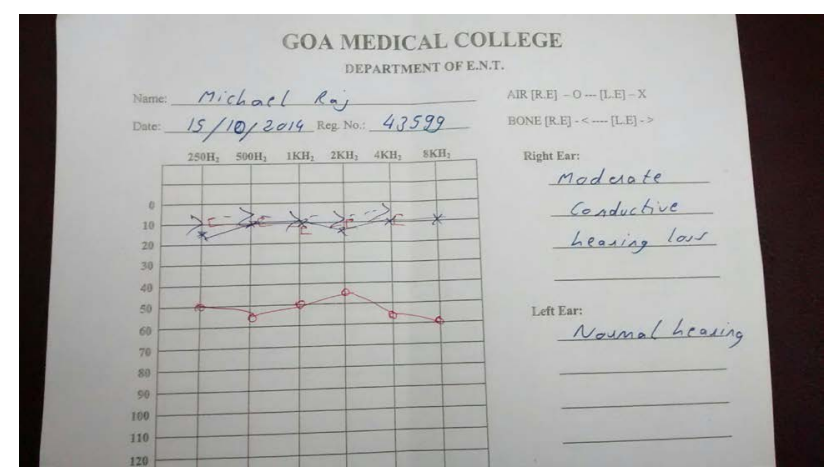

Figure 1. Pure tone audiometry (preoperative findings).

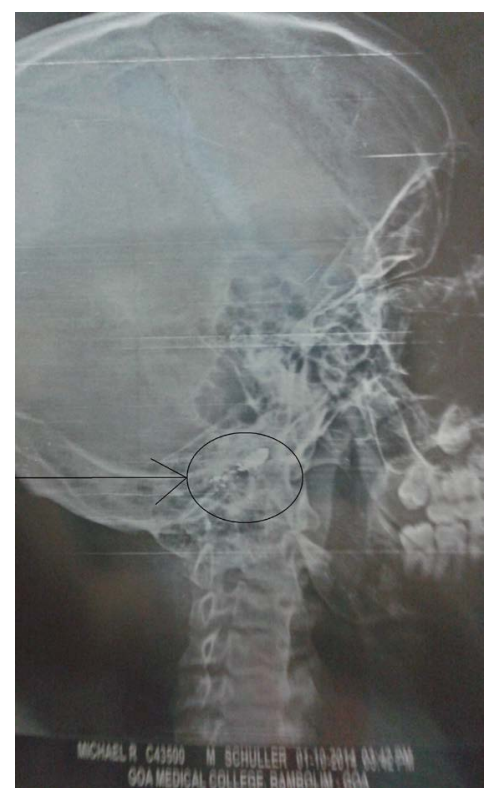

Figure 2. X-ray mastoid showing foreign body anterior to external acoustic meatus. 


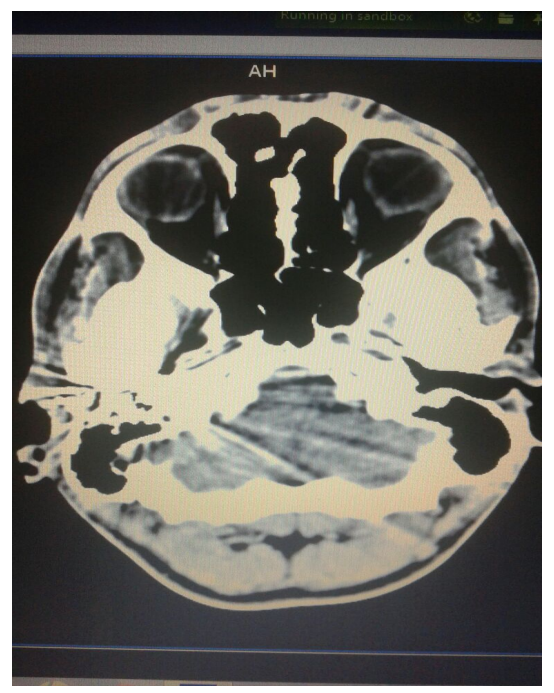

Figure 3. HRCT temporal bone showing multiple artefacts with streaking in the external auditory canal and middle ear.

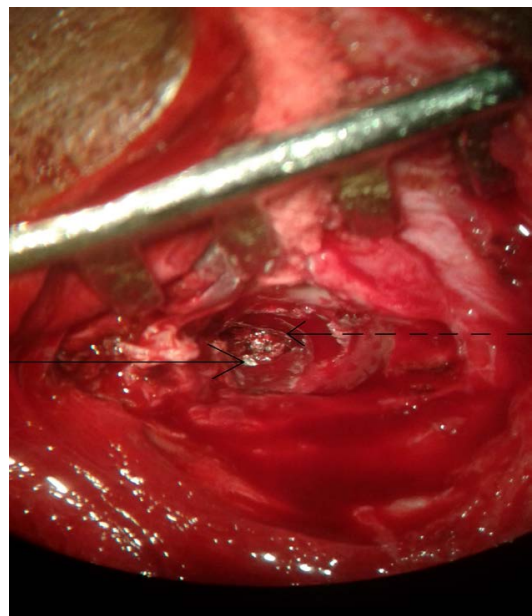

Figure 4. Showing metallic foreign body (bullet) in middle ear through ruptured tympanic membrane following posterior meatotomy. Dotted arrow showing ruptured tympanic membrane and solid arrow showing metallic foreign body (bullet).

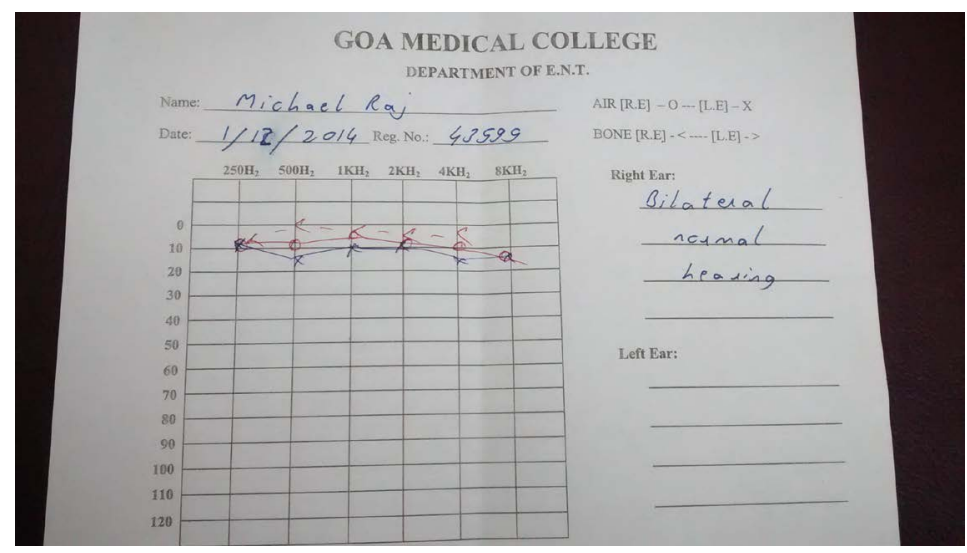

Figure 5. Pure tone audiometry (post operative findings). 


\section{Discussion}

Bullet wound could be ricocheting shots or grazing ones. While some shots leave bullets lodged in the body, others have an exit wound. The location of an entrance wound and the projectile path are the most important factors in causing significant injury or death following shooting [1]. The extent of tissue damage is influenced by the type of bullet, its velocity and mass as well as the physical characteristics of tissues [2]. Gun-shot injuries are characterized by irregular path as well as localised destruction of bones and tissues [1].

Penetrating injuries to the middle ear could be due to misguided cotton tip, hairpin, key or pencil/pen. Blast injuries are also counted under penetrating injuries. However penetrating bullet injuries through the external auditory canal are considered among the rarest of the rare cases. Injuries caused by the afore mentioned objects are usually localized and often have a predictable path as compared to the bullet injuries which don't [3].

Handguns and shotguns are generally low velocity $(<1000$ frequency/second), unless fired at close range. Rifles usually project high velocity missiles ( $>2000$ frequency/second). Skin is penetrated by a projectile at the rate about 163 frequency/second while bone requires 213 frequency/second to fracture [3]. The bullet which was found in our case measured 0.177 caliber $(4.5 \mathrm{~mm})$.

Whatever the case, the presentation is almost similar viz-pain, conductive hearing loss, sensorineural hearing loss, vertigo, tinnitus, rarely dysguesia/facial palsy. Delayed effects like infections, otorrhoea and tertiary cholesteatoma may also result [3].

Upto $88 \%$ of traumatic tympanic membrane perforations heal spontaneously within 3 - 10 months. The rate of spontaneous healing is inversely proportional to the size of perforation. Perforations that do not heal spontaneously within this time may require tympanoplasty to reduce the risk of chronic infection or cholesteatoma. In Kronenburg and colleagues series, the risk of post injury cholesteatoma was limited to patients whose perforation did not heal in 10 months [4].

Our main objective in the particular case was to remove the foreign body, reconstruct the middle ear, achieve fairly normal hearing and prevent tertiary choleasteatoma formation.

In this particular case, as the bullet entered through the external auditory canal and was lodged in the middle ear extra complications of bullet path and cavity did not come into play. The fragile tympanic membrane was damaged. This being a low velocity missile, the bullet had lost a significant amount of velocity by the time it entered the middle ear. The firing range is assumed to be long as the patient claimed to have not seen the assailant. Even though the patient's hearing returned back to normal, the patient has to be followed up indefinitely for the fear of cholesteatoma formation.

\section{Conclusion}

Penetrating bullet injury to the ear with virtually no entry wound is a rare occurrence. Even though we removed the foreign body and achieved an intact ear drum and a normal hearing post operatively, the patient has to be followed up indefinitely for the fear of tertiary cholesteatoma formation.

\section{References}

[1] Reiss, M., Reiss, G. and Pilling, E. (1998) Gunshot Injuries in Head and Neck Area. Basic Principles, Diagnosis and Management. Schweizerische Rundschav fur Medizin Praxis, 87, 832-838.

[2] Maiden, N. (2009) Ballistics Review: Mechanisms of Bullet Wound Trauma. Forensic Science, Medicine, and Pathology, 5, 204-209. http://dx.doi.org/10.1007/s12024-009-9096-6

[3] Willings, D.B. and Pacher, M.D.N. (2009) Trauma to Middle Ear, Inner Ear and Temporal Bone. Ballingers Otorhinolaryngology. Head and Neck Surgery, 1.

[4] Kronenberg, J., Ben-Shoshan, J. and Wolf, M. (1993) Perforated Tympanic Membrane after Blast Injury. American Journal of Otolaryngology, 14, 92-94. 
Scientific Research Publishing (SCIRP) is one of the largest Open Access journal publishers. It is currently publishing more than 200 open access, online, peer-reviewed journals covering a wide range of academic disciplines. SCIRP serves the worldwide academic communities and contributes to the progress and application of science with its publication.

Other selected journals from SCIRP are listed as below. Submit your manuscript to us via either submit@scirp.org or Online Submission Portal.
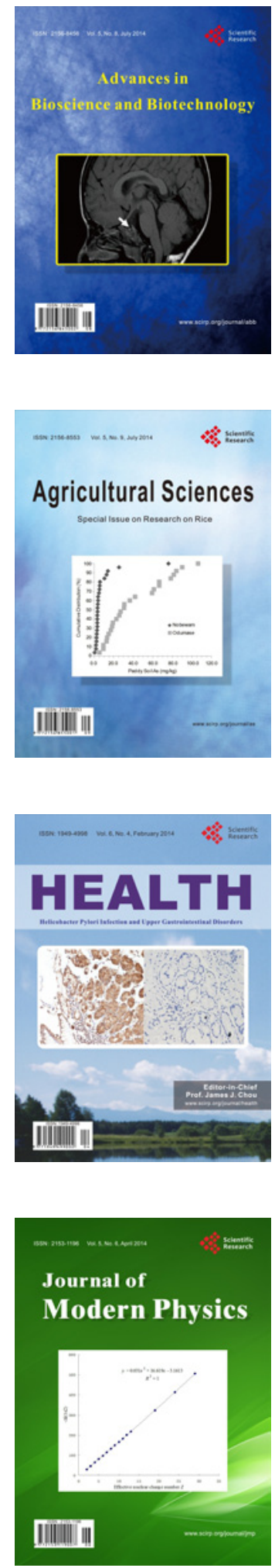
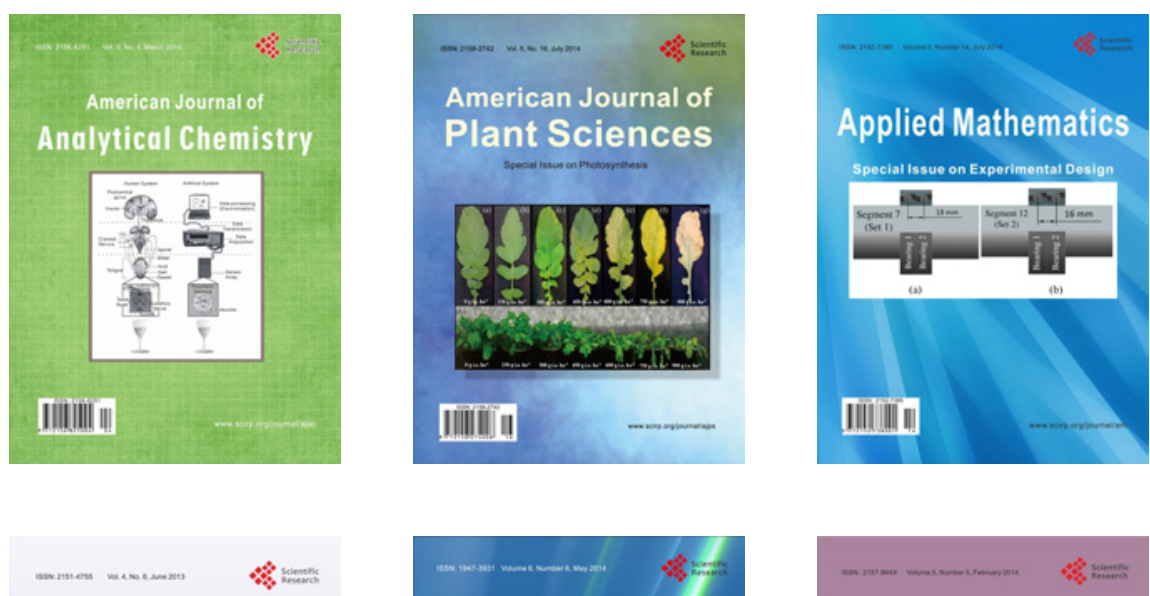

Creative Education
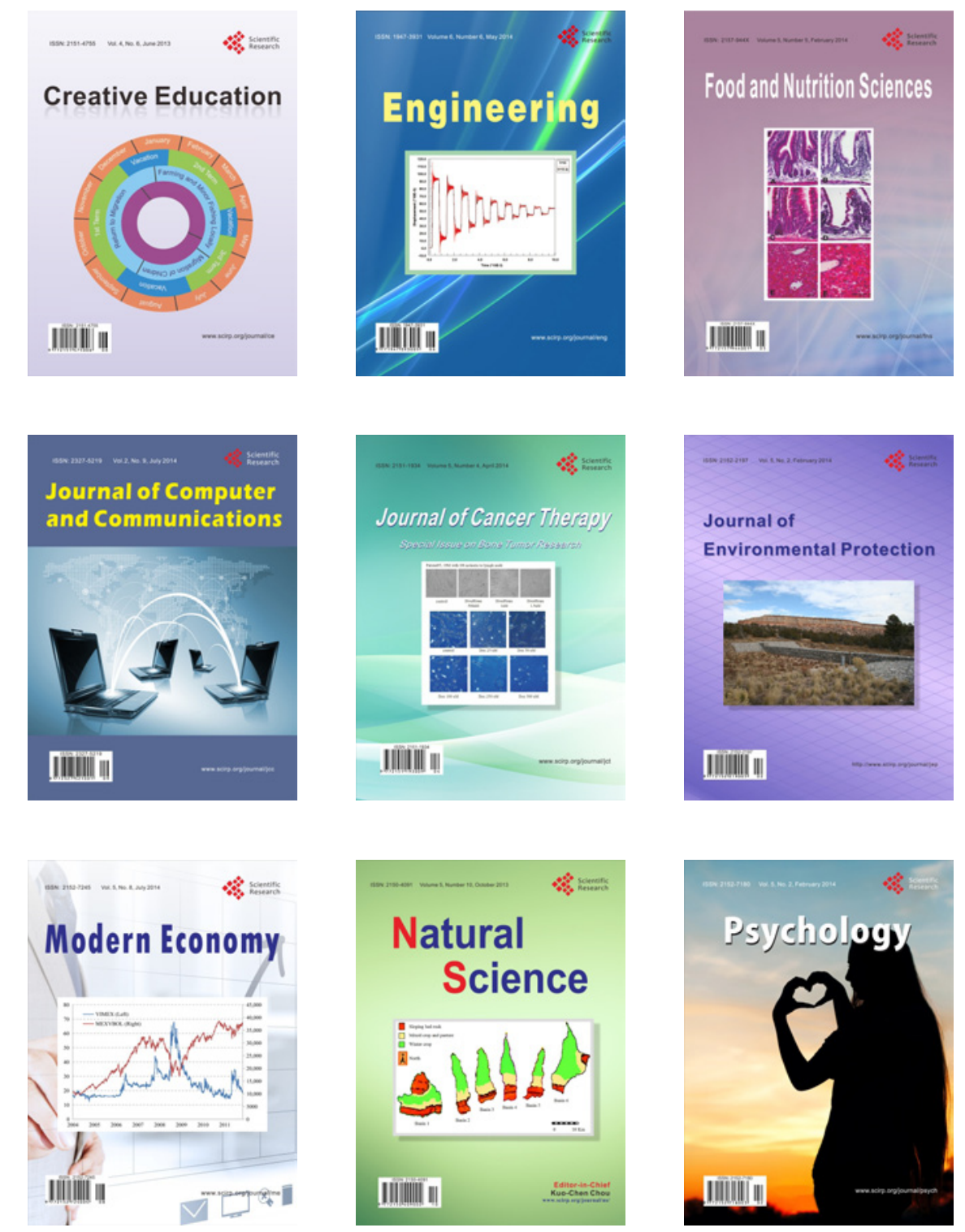